\title{
Oficina de reflexão de práticas pedagógicas sob a ótica do uso de metodologias ativas
}

\author{
Ernandes Gonçalves Dias \\ Enfermeiro. Mestre em Ciências. Docente na Faculdade Verde Norte (Favenorte) \\ $\square$ ernandesgdias@yahoo.com.br \\ Cleiciane Faria Soares \\ Engenheira Ambiental. Especialista em Engenharia de Segurança do Trabalho \\ Docente na Faculdade Verde Norte (Favenorte) \\ $\triangle$ cleicianeprof@gmail.com \\ Cleonice Corrêa Fonseca \\ Pedagoga. Especialista em Educação. Assessora pedagógica na Faculdade Verde Norte (Favenorte) \\ $\triangle$ cleofonsecacorrea@yahoo.com.br
}

\section{Resumo:}

Refletir as práticas pedagógicas praticadas por docentes do ensino superior é necessário para o avanço na qualidade do ensino, aperfeiçoamento profissional e crescimento e alcance de indicadores pelas Instituições de Ensino Superior. A realização de oficinas pedagógicas com docentes pode estimular que estes profissionais se motivem e reflitam sobre a importância do uso de metodologias ativas no processo de ensino e aprendizagem. Objetivou-se provocar inquietações e estimular os docentes a trocar experiências quanto às práticas e adoção de metodologias ativas no processo de ensino e aprendizagem na IES. O método empregado na Oficina remete a um estudo de caso com abordagem qualitativa. As atividades foram organizadas em cinco blocos, o primeiro compreendeu acolhimento e abertura dos docentes participantes, seguido por uma rodada de questões disparadoras de discussão com três questões reflexivas, o terceiro uma e o quarto com duas questões também disparadoras e o quinto bloco com apresentação de uma síntese crítica a partir dos relatos e argumentos expostos pelos docentes e avaliação da oficina. As produções elaboradas na Oficina mostram que os docentes adotam o uso metodologias ativas nas aulas, reconhecem o cenário de atuação da IES e público que atende, têm visão bastante positiva em relação à sua formação e prática profissional e menos positiva em relação aos acadêmicos sob sua responsabilidade de formação.

Palavras-chave: Metodologia, Métodos, Ensino, Educação Superior.

\section{Workshop on reflection pedagogical practices under the lens on the use of active methodologies}

\begin{abstract}
:
Reflecting the pedagogical practices practiced by higher education teachers is necessary for the advancement in the quality of teaching, professional improvement and growth and reach of indicators by Higher Education Institutions. The realization of pedagogical workshops with teachers can stimulate these professionals to motivate and reflect on the importance of the use of active methodologies in the teaching and learning process. The objective was to provoke anxiety and encourage teachers to exchange experiences about practices and adoption of active methodologies in the teaching and learning process in HEI. The method used in the Workshop refers to a case study with a qualitative approach. The activities were organized in five blocks, the first comprised the reception and opening of the participating teachers, followed by a round of questions of discussion with three reflective questions, the third one and the fourth with two triggers and the fifth block with presentation a critical synthesis from the reports and arguments presented by the teachers and
\end{abstract}


evaluation of the workshop. The productions elaborated in the Workshop show that teachers use active methodologies in class, recognize the scenario of the performance of the IES and the attending public, have a very positive view regarding their professional training and practice and are less positive in relation to the academics under their supervision responsibility.

Keywords: Methodology, Methods, Teaching, Education, Higher.

\section{Taller sobre la reflexión de las prácticas pedagógicas desde la perspectiva del uso de metodologías activas}

\section{Resumen:}

Es necesario reflejar las prácticas pedagógicas practicadas por los docentes de educación superior para el avance de la calidad de la enseñanza, la mejora profesional y el crecimiento y el logro de indicadores por parte de las instituciones de educación superior. La celebración de talleres pedagógicos con docentes puede alentar a estos profesionales a motivarse y reflexionar sobre la importancia de utilizar metodologías activas en el proceso de enseñanza y aprendizaje. El objetivo era provocar inquietudes y alentar a los docentes a intercambiar experiencias sobre prácticas y la adopción de metodologías activas en el proceso de enseñanza y aprendizaje en HEI. El método utilizado en el Taller se refiere a un estudio de caso con un enfoque cualitativo. Las actividades se organizaron en cinco bloques, el primero comprendió la bienvenida y la apertura de los maestros participantes, seguido de una ronda de preguntas de discusión con tres preguntas reflexivas, la tercera y la cuarta con dos preguntas de activación y el quinto bloque con la presentación de Una síntesis crítica de los informes y argumentos expuestos por los docentes y la evaluación del taller. Las producciones elaboradas en el Taller muestran que los maestros adoptan el uso de metodologías activas en las clases, reconocen el escenario de desempeño de la IES y el público al que sirve, tienen una visión muy positiva en relación con su formación y práctica profesional y menos positiva en relación con los académicos bajo su responsabilidad. Responsabilidad de formación.

Palabras clave: Metodología, Métodos, Enseñanza, Educación Superior.

\section{INTRODUÇÃO}

Qualificar a docência envolve ações de capacitação e formação de docentes, que se operacionaliza na criação de espaços para reflexão, diálogo e escuta sobre a própria prática educativa. Isto posto, propicia-se a construção de uma cultura de estudo, produção e socialização de conhecimentos entre os docentes (FREITAS et al., 2010).

As atividades práticas caracterizam como uma boa estratégia de ensino, especialmente aquelas realizadas em grupo, como são as oficinas. As oficinas promovem maior interação entre os sujeitos da aprendizagem e facilitam atingir os objetivos em foco (SOUZA, 2016).

Oficinas pedagógicas contribuem deforma significativa para a formação de professores. Elas são uma alternativa para o desenvolvimento dos saberes necessários ao docente, ajudam na produção e desenvolvimento de conhecimentos em áreas específicas, e, 
sobretudo podem influenciar na prática do docente, devido às suas características de possibilitarem trocar experiências e debater sobre diferentes pontos de vista (FONSECA; MENDES, 2012).

Refletir as práticas pedagógicas praticadas por docentes do ensino superior é necessário para o avanço na qualidade do ensino, aperfeiçoamento profissional e crescimento e alcance de indicadores pelas Instituições de Ensino Superior (IES).

A necessidade da realização da oficina surgiu a partir de incentivo e recomendação da assessoria pedagógica da IES para o uso de metodologias ativas de ensino e aprendizagem, pelos docentes, durante as aulas a fim de tornar as aulas mais dinâmicas e os acadêmicos mais ativos em sua aprendizagem. Assim, o objetivo da oficina foi provocar inquietações e estimular os docentes a trocar experiências quanto às práticas e adoção de metodologias ativas no processo de ensino e aprendizagem na IES.

A oficina foi organizada por dois docentes da própria IES que exerceram a função de moderadores das atividades. As atividades foram organizadas em cinco blocos, o primeiro compreendeu acolhimento e abertura dos docentes participantes, o segundo foi uma rodada de questões disparadoras de discussão com três questões reflexivas, o terceiro com uma questão, o quarto com duas questões também disparadoras e o quinto a apresentação de uma síntese crítica a partir dos relatos e argumentos expostos pelos docentes e avaliação da oficina. O método empregado na Oficina remete a um estudo de caso com abordagem qualitativa.

\section{DESENVOLVIMENTO DA OFICINA}

\section{Operacionalização da oficina}

Para realizar a oficina foi necessário criar um ambiente amistoso (temperatura, iluminação e decoração adequados) em espaço físico compatível à quantidade de participantes, ainda foram necessários os recursos: folhas sem pauta, pinceis atômicos finos, cartolinas, tesoura, fita adesiva, caixa de som, notebook e projetor de imagens. 
Participaram da oficina 27 docentes dos diversos cursos superiores e técnicos da IES por um período de quatro horas de atividades. Antes de iniciar as tarefas os moderadores esclareceram a importância do cumprimento dos tempos protocolares de cada tarefa, visto que isto fazia parte da dinâmica de trabalho.

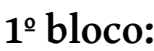

O primeiro bloco de atividades iniciou com a recepção dos docentes, enquanto eram recepcionados rolava músicas motivacionais (Voo do beija flor da Elisa Cristal; Best day of my life de American Authors) para deixar o ambiente mais receptivo e os docentes mais relaxados e abertos a conversa. Ainda no primeiro bloco teve-se uma breve abertura realizada pela assessora pedagógica da IES para explicar a finalidade da oficina.

\section{2o bloco:}

A partir do bloco dois todas as atividades foram coordenadas por dois moderadores também docentes da IES. A primeira orientação foi dividir os docentes em grupos, assim, montou-se três grupos de cinco docentes e dois grupos de seis docentes. Cada grupo elegeu um coordenador de grupo, com atribuição de organização da discussão em grupo e fazer a gestão do tempo, e um relator, com a função de anotar, sintetizar e apresentar aos demais grupos a produção do grupo. Pela dinâmica do trabalho convencionou-se o coordenador ser papel fixo de um membro e a relatoria ser exercida por diversos membros de um grupo nas várias rodadas de apresentações.

Após os grupos montados e papeis definidos foi entregue para cada coordenador de grupo folhas sem pauta, pincel atômico fino e três questões para discussão: Quem são nossos alunos? Que tipo de professores somos? o que são metodologias ativas? (Figura 1).

Os grupos tiveram 10 minutos para discutir e sintetizar respostas para as três questões, as respostas deveriam ser anotadas em folhas sem pauta, em separado, em tópicos, para posterior apresentação para os demais grupos, pelo relator.

Finalizado o tempo um moderador convidou os relatores de grupo para expor a resposta da primeira questão, depois de todos os grupos exporem reiniciou-se as apresentações com as respostas da segunda e depois da terceira questão. Durante as 
apresentações o segundo moderador digitava as palavras-chaves das respostas dos grupos para cada questão.

Após a exposição cada relator fixava seu cartaz resposta na parede da sala, em local indicado por uma placa orientadora fixada pelos moderadores para ao final de cada questão discutida ter montado um painel integrado. Ao final do bloco 2 foi servido um coffee break.

Figura 1. Questões disparadoras da discussão entre os grupos: Quem são nossos alunos? Que tipo de professores somos? O que são metodologias ativas?
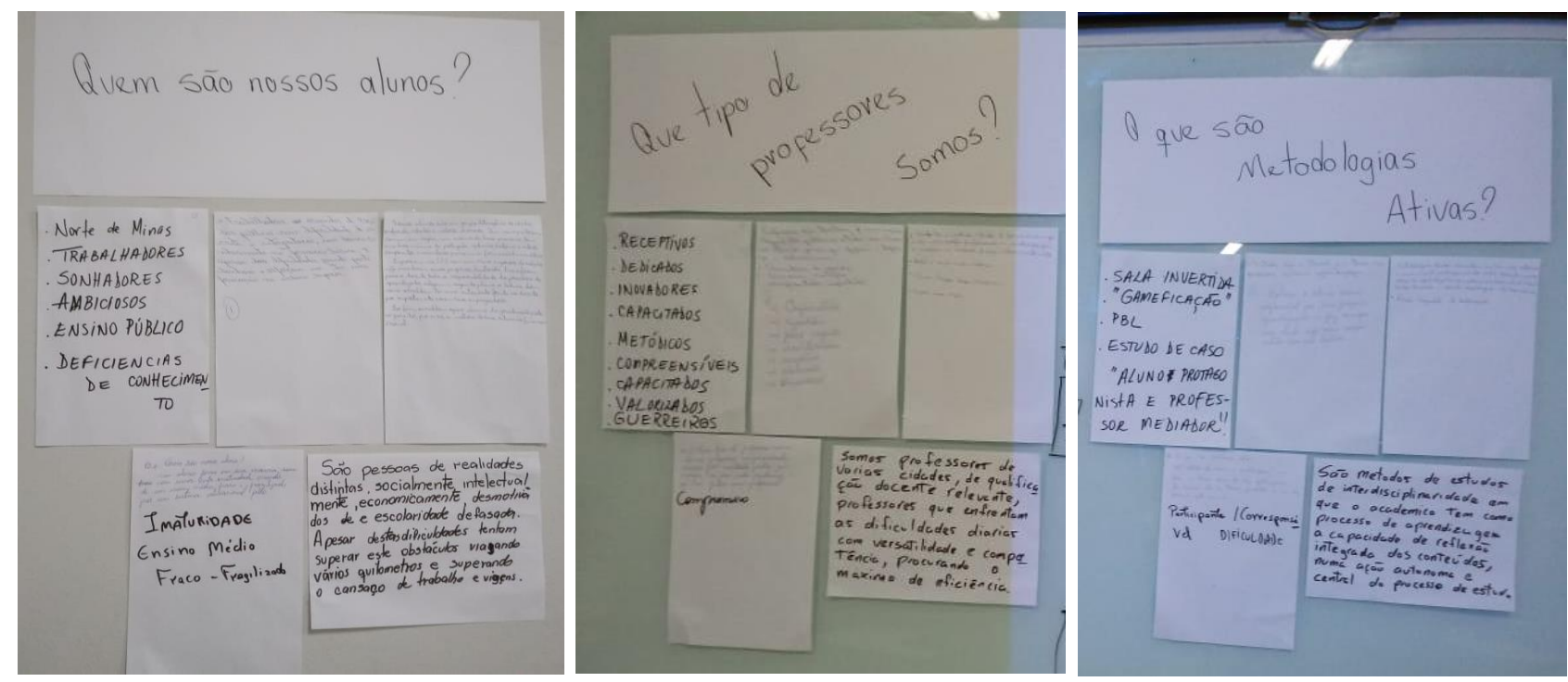

Fonte: Imagens dos autores. 2019.

O uso do painel é um importante recurso para auxiliar o desenvolvimento da aula, permite fazer desse momento uma oportunidade para interação e assimilação de conteúdo, assim como possibilita aos participantes o desenvolvimento de autonomia, iniciativa e reflexão a partir da construção do painel (INOCENTE; CASTAMAN; VIEIRA, 2017).

\section{3o bloco:}

O terceiro bloco iniciou após o coffee break com os docentes reposicionados em seus grupos de trabalho. Mais uma vez cada coordenador recebeu uma questão disparadora de discussão com tempo de cinco minutos para elaborar resposta. 
Neste bloco a questão foi: o que faço em meu componente curricular que entendo ser uma metodologia ativa? O grupo deveria entrar em consenso e destacar duas experiências para compartilhar com demais grupos na apresentação do relator dessa tarefa (Figura 2). Na apresentação além de indicar qual nome da metodologia, também explicar como é executada em sala.

Findado o prazo de discussões iniciou-se as exposições seguindo os mesmos princípios da apresentação do segundo bloco, com também, digitação de palavras-chaves das respostas por um moderador e fixação dos cartazes em espaços indicados para montar o painel.

Figura 2. Questões disparadoras da discussão entre os grupos: O que faço em meu componente curricular que entendo ser uma metodologia ativa?

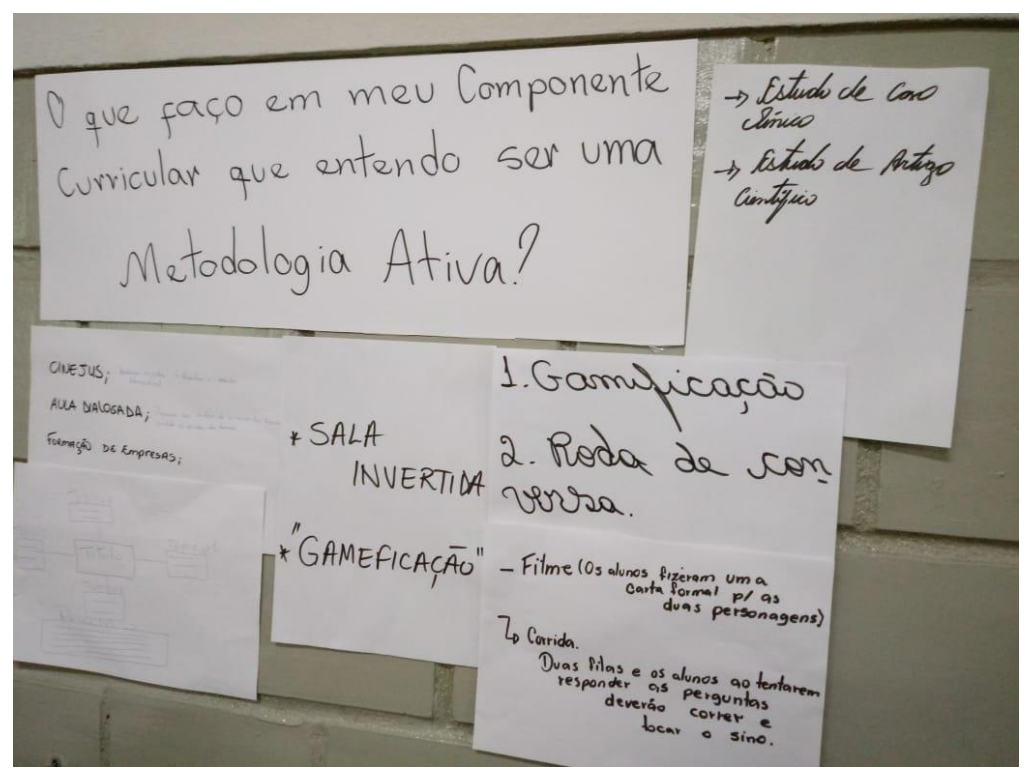

Fonte: Imagens dos autores. 2019.

Os docentes conseguiram expor diferentes estratégias de metodologias ativas que trabalham em sala de aula para tornar as aulas mais dinâmicas e despertar no acadêmico e o interesse pelos tópicos de estudo. Emergiram nas apresentações as metodologias Estudo de caso, Roda de conversas, Gamificação, Sala de aula invertida, Cine vídeo entre outras.

As metodologias ativas são, atualmente, uma tendência pedagógica para o ensino e aprendizagem pelo fato de se tratar de estratégias que colocam o acadêmico como 
corresponsável por sua trajetória educacional. No uso dessas metodologias o professor assume o papel de articulador e facilitador do processo (BAGATINI; SCHORR, 2019).

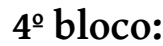

Para iniciar o quarto bloco um moderador deu comando de que todos assistissem no projetor de imagens, ao vídeo explicativo da metodologia "Tempestades de Ideias" e realizassem a atividade de execução desta técnica respondendo à questão: o que em sala de aula é um dificultador/fragilidade para educar pelo uso de metodologias ativas? (Figura 3). Contudo, para iniciar a tarefa era preciso aguardar comando do próprio vídeo, depois de autorizado o grupo tinha três minutos para formular um consenso para posterior apresentação. Quando o vídeo finalizasse também finalizaria o tempo para elaboração da resposta.

Figura 3. Tempestade de ideias: o que em sala de aula é um dificultador/fragilidade para educar pelo uso de metodologias ativas?

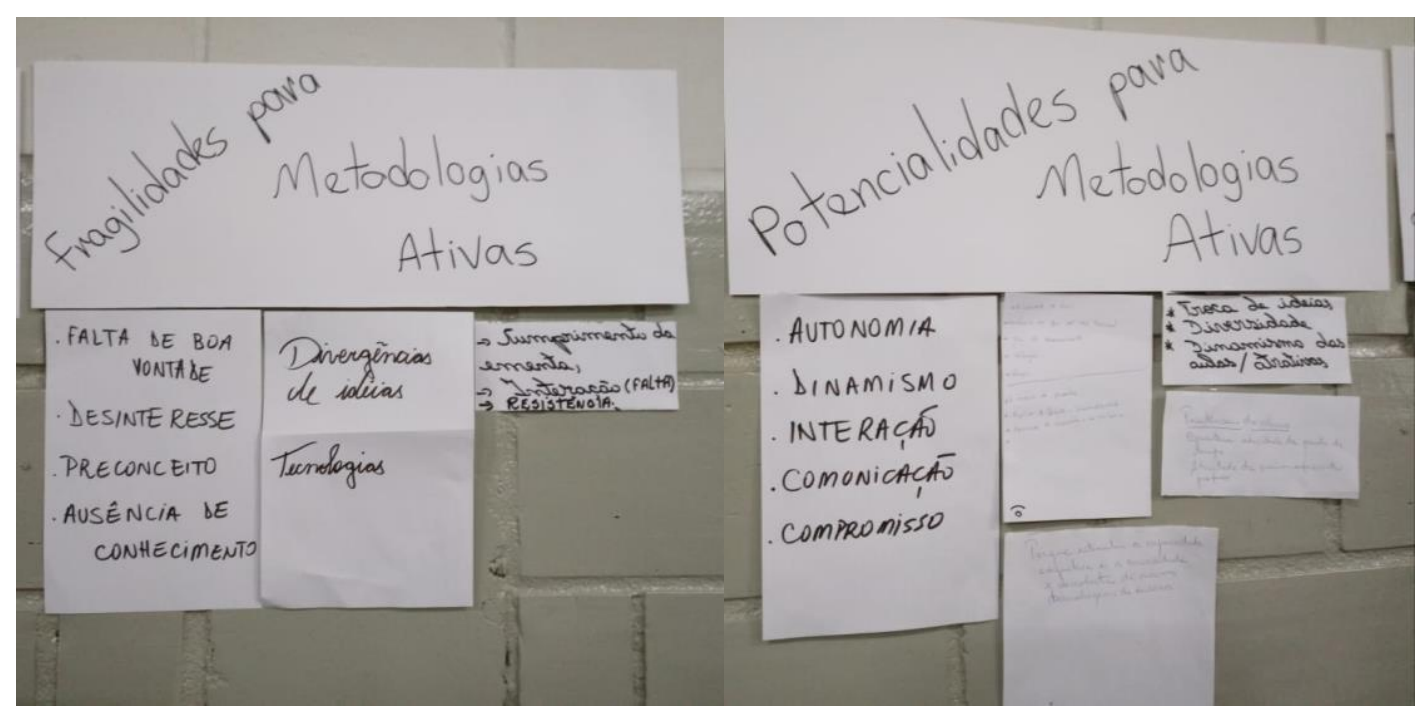

Fonte: Imagens dos autores. 2019.

Respondida a primeira questão o vídeo era reiniciado a partir do comando de iniciar tarefa para agora os grupos responderem à questão: o que em sala de aula é um potencial para educar pelo uso de metodologias ativas? Para essa tarefa também se seguia as mesmas orientações para a questão anterior. 
A Tempestade de ideias ou Brainstorming é uma técnica de reunião coletiva, também usada como estratégia de ensino em grupo onde a principal característica é explorar a criatividade do grupo. Utiliza-se para estimular o pensamento criativo e facilitar o planejamento e permite ao grupo gerar e organizar suas ideias (MICHELATO, 2013).

O uso de vídeos como estratégias de ensino e aprendizagem permitem a expressão das ideias para além de conteúdos escolares (BORBA; OECHSLER, 2018). O vídeo que subsidiou essa tarefa foi baixado da plataforma do Youtube usando o aplicativo Atube Catcher. O vídeo em questão está disponível para acesso público pelo link: https://www.youtube.com/watch?v=5w7hCFtErC8.

Depois de respondida as duas questões os relatores de cada pergunta fizeram a exposição para os demais grupos, seguindo a dinâmica de apresentação das demais questões anteriores. As palavras-chave de respostas destas questões também foram digitadas por um dos moderadores, e também construídos painéis integrados com os cartazes.

\section{5o bloco:}

O quinto e último bloco da oficina foi iniciado com a dinâmica (bola da magia) acompanhada da música (Carol ann de Michel W. Smit) orientada por uma moderadora.

A dinâmica bola da magia objetiva incentivar as pessoas a extrair a sua melhor parte e compartilhar com os demais em sua volta. Para tanto, foi solicitado aos participantes que tocassem em seu corpo onde tivesse sua maior concentração de energia positiva. A partir de então, cada participante idealizou pegar um pouquinho dessa energia em sua mão e começou a enrolar formando uma bola. À medida que foram instruídos a dispor de mais energia, essa bola em suas mãos fora crescendo. Orientados a buscar energia de todo o ambiente, a bola da magia se formou gigantesca, deixando o participante com dificuldades de segurar sozinho toda aquela energia positiva canalizada naquela bola imaginária de energia.

Solicitou-se então, que cada participante dividisse com os demais a sua bola da magia. Ao jogar para cima, toda a energia boa canalizada naquela bola se espalhou por todo o ambiente e cada participante, guiado pela mediadora, começou a recolher para si o quanto pode de toda a energia das bolas. Conclui-se refletindo sobre a importância de cada pessoa 
diariamente estar pronta para espalhar energias positivas por onde passar, assim, também estará recebendo toda a positividade dos de sua convivência.

Ao finalizar a dinâmica, realizou-se o sorteio de chocolates para os participantes usando o aplicativo de celular Sorteio Rápido, disponível gratuitamente para dispositivos com sistema Android, que sorteia aleatoriamente, números que correspondiam a ordem numérica da lista de presença.

O uso de dinâmicas de grupo é uma prática pedagógica que favorece o desenvolvimento de competências e habilidades. A aprendizagem mediante dinâmicas de grupo pode se efetivar como inovadoras no ensino quando trabalhadas em sintonia com o conteúdo teórico, planejada em ações e objetivos a serem alcançados (ALBERTI et al., 2014).

Enquanto a dinâmica se processava outro moderador aplicava as palavras-chave das respostas a cada pergunta realizada desde o primeiro bloco da oficina, ao aplicativo Wordle para gerar nuvens de palavras (Figuras 4 a 9). As nuvens geradas foram salvas e inseridas em telas de slides do PowerPoint para apresentação e síntese das discussões ocorridas no desenrolar da dinâmica.

Abaixo observa-se a sequência de telas geradas pelo aplicativo Wordle.

Figura 4. Quem são nossos alunos?

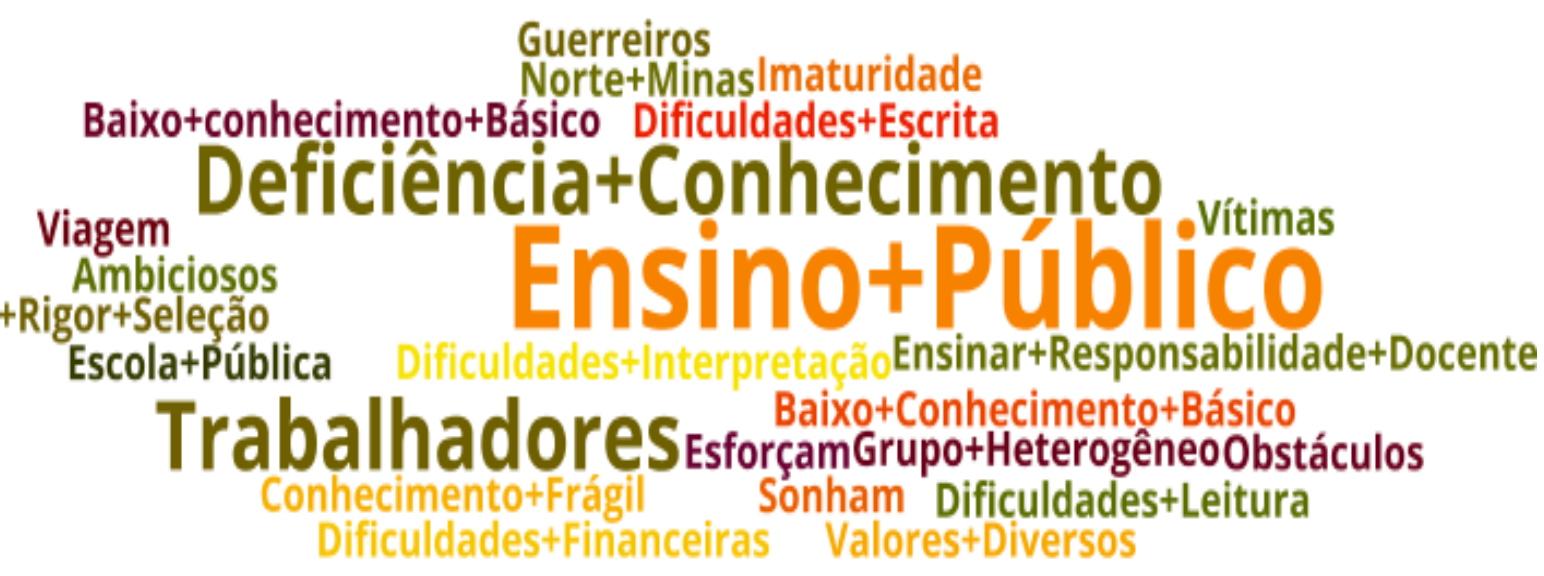

Fonte: Imagem do Wordle gerada pelos autores. 2019. 
Figura 5. Que tipo de professores somos?

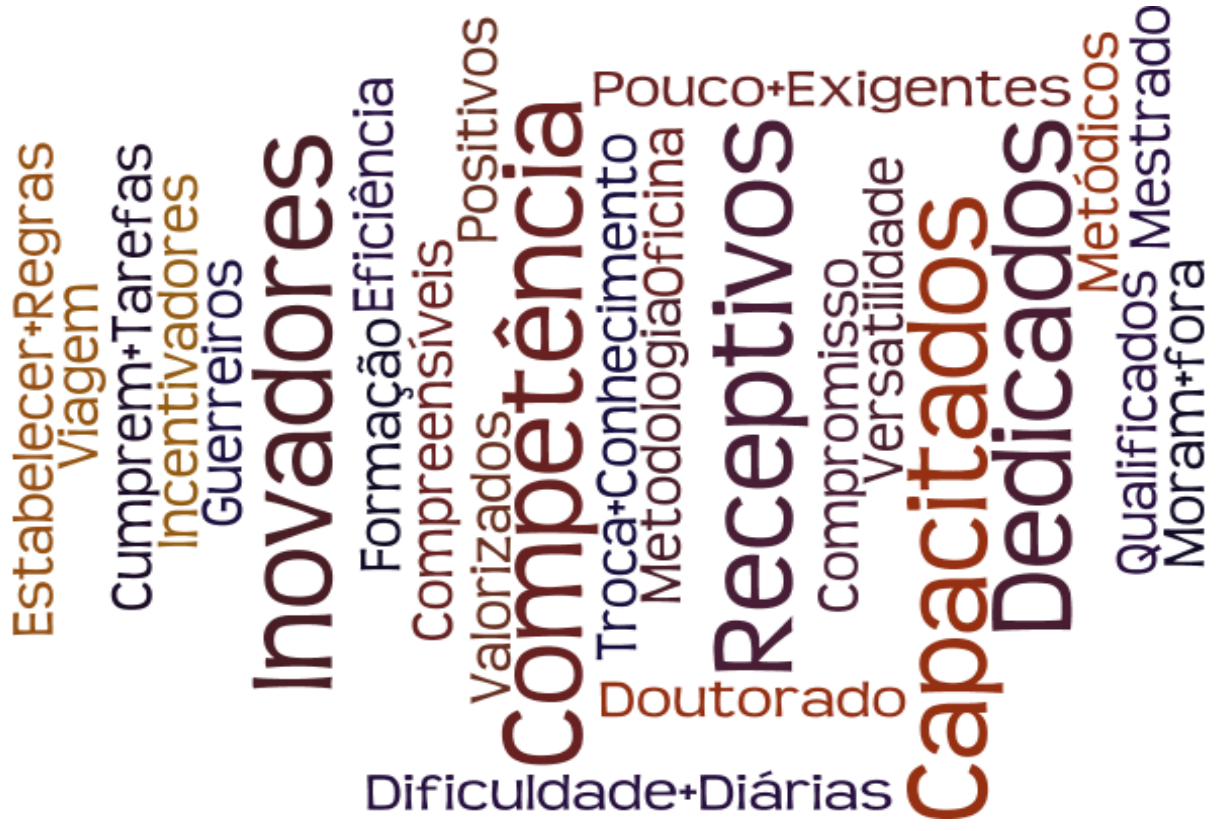

Fonte: Imagem do Wordle gerada pelos autores. 2019.

Figura 6. O que são metodologias ativas?

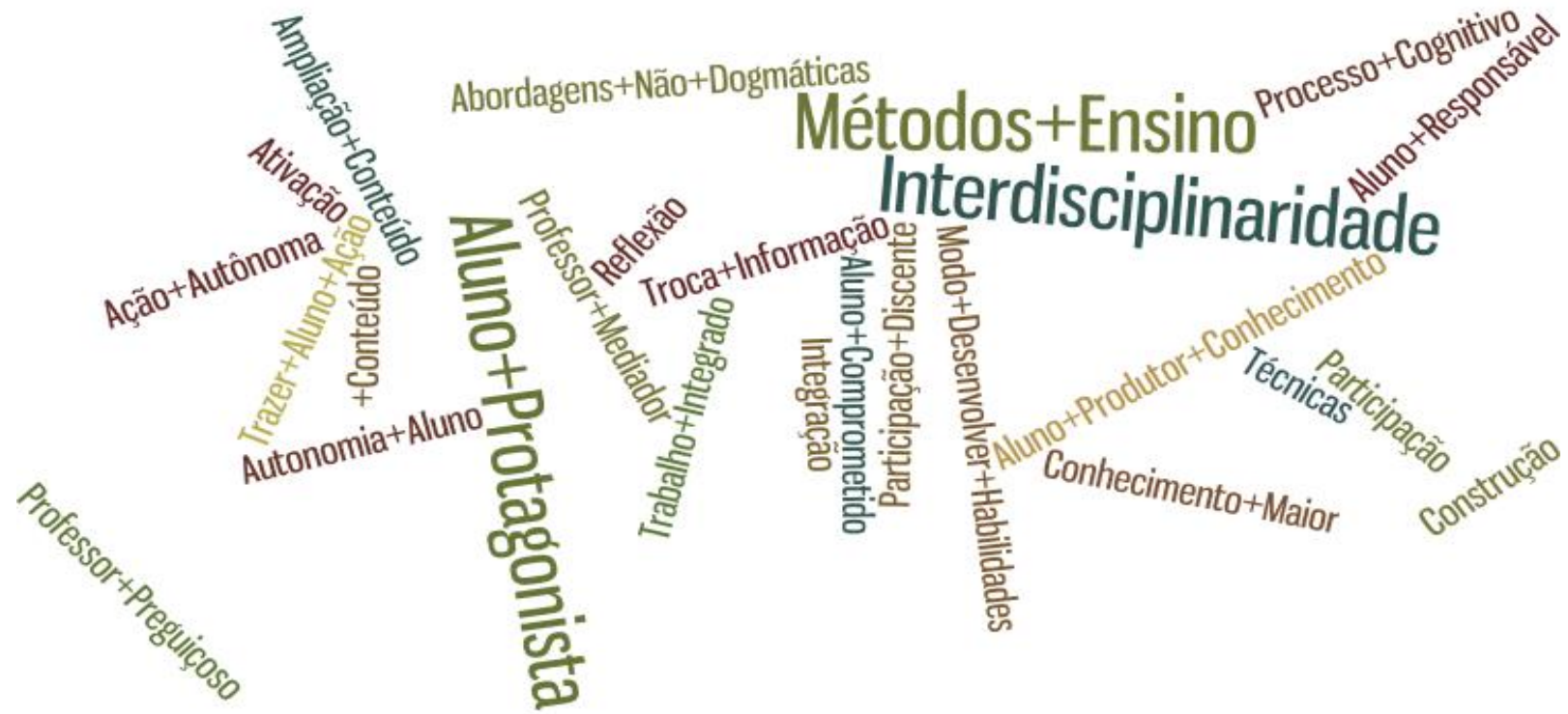

Fonte: Imagem do Wordle gerada pelos autores. 2019. 
Figura 7. 0 que faço em meu componente curricular que entendo ser uma metodologia ativa?

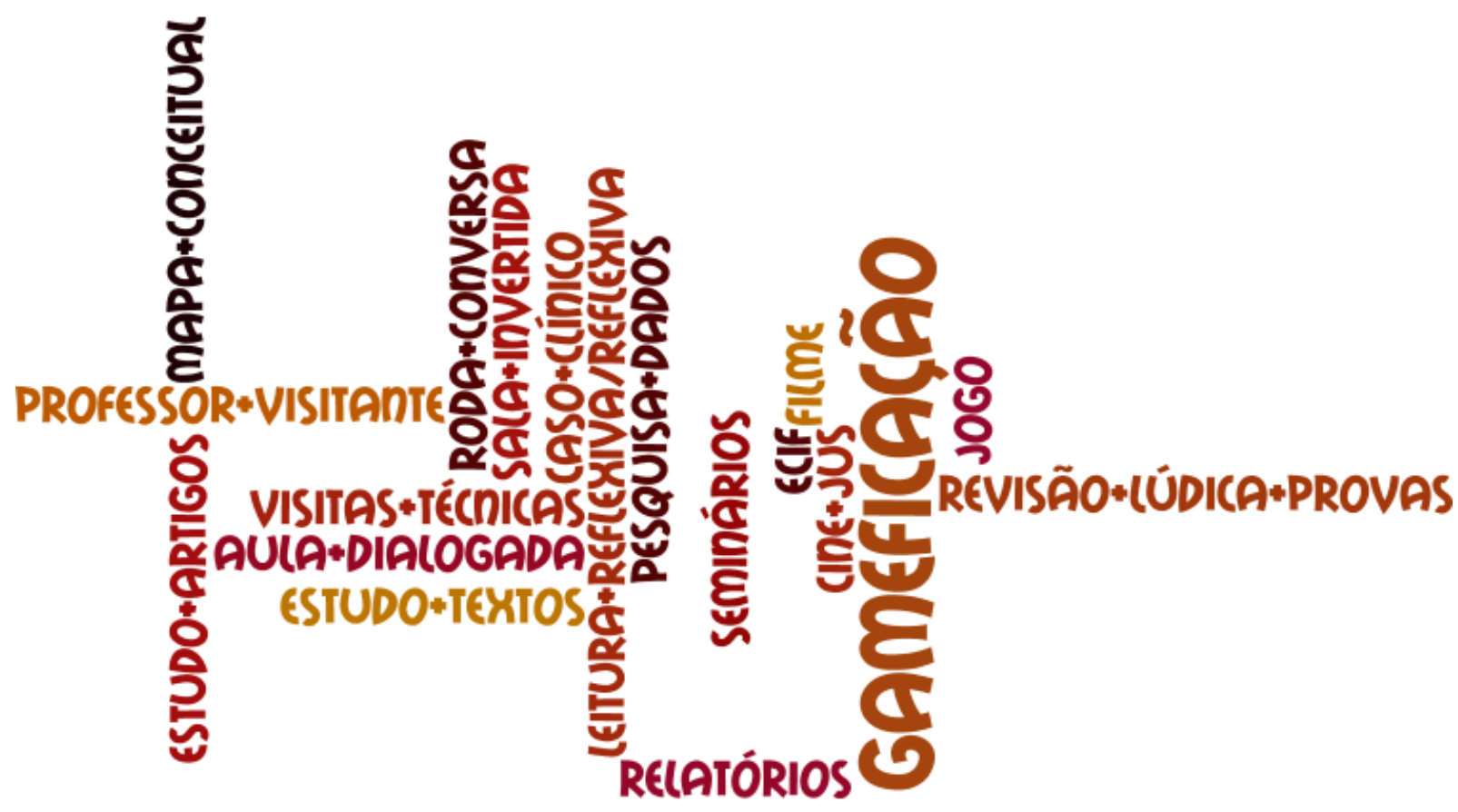

Fonte: Imagem do Wordle gerada pelos autores. 2019.

Figura 8. O que em sala de aula é um dificultador/fragilidade para educar pelo uso de metodologias ativas?

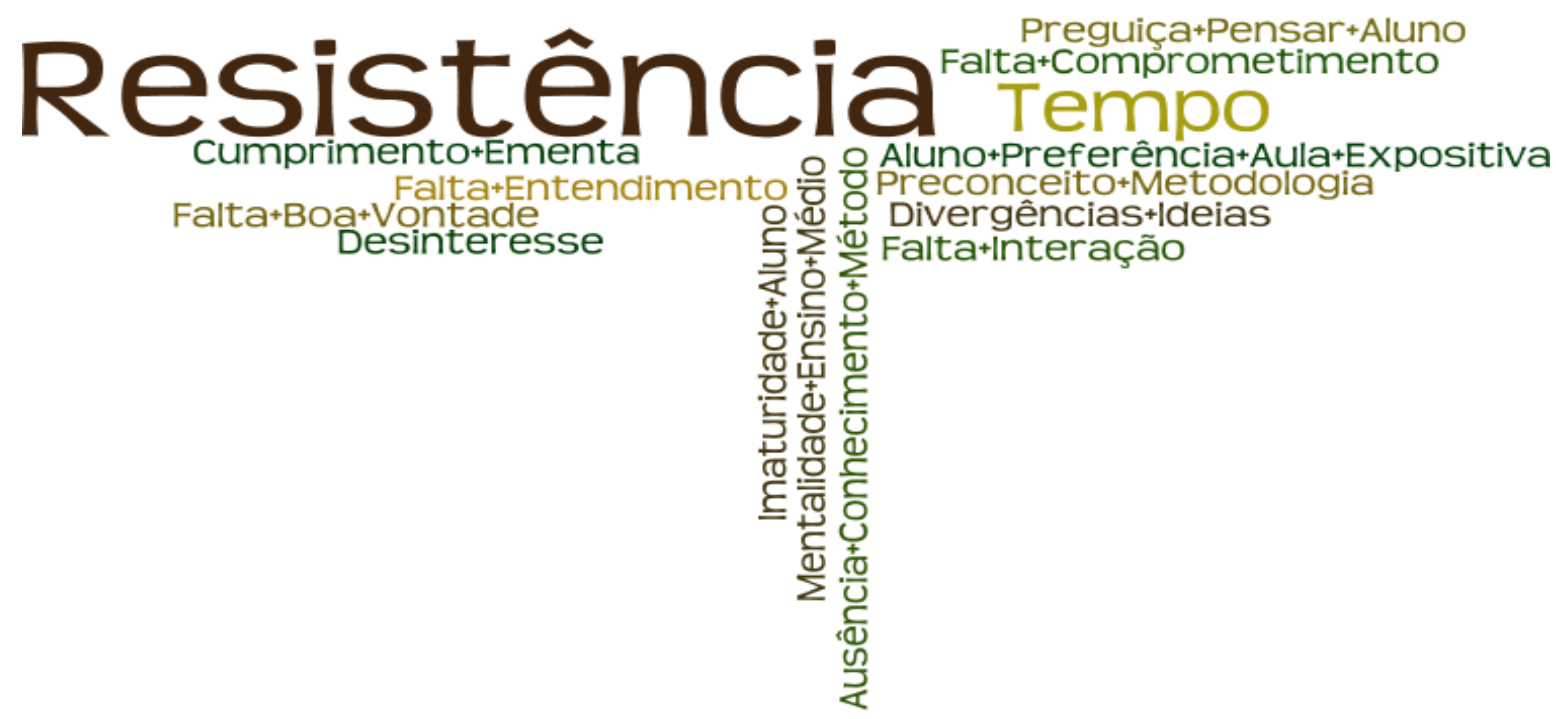

Fonte: Imagem do Wordle gerada pelos autores. 2019. 
Figura 9. O que em sala de aula é um potencial para educar pelo uso de metodologias ativas?

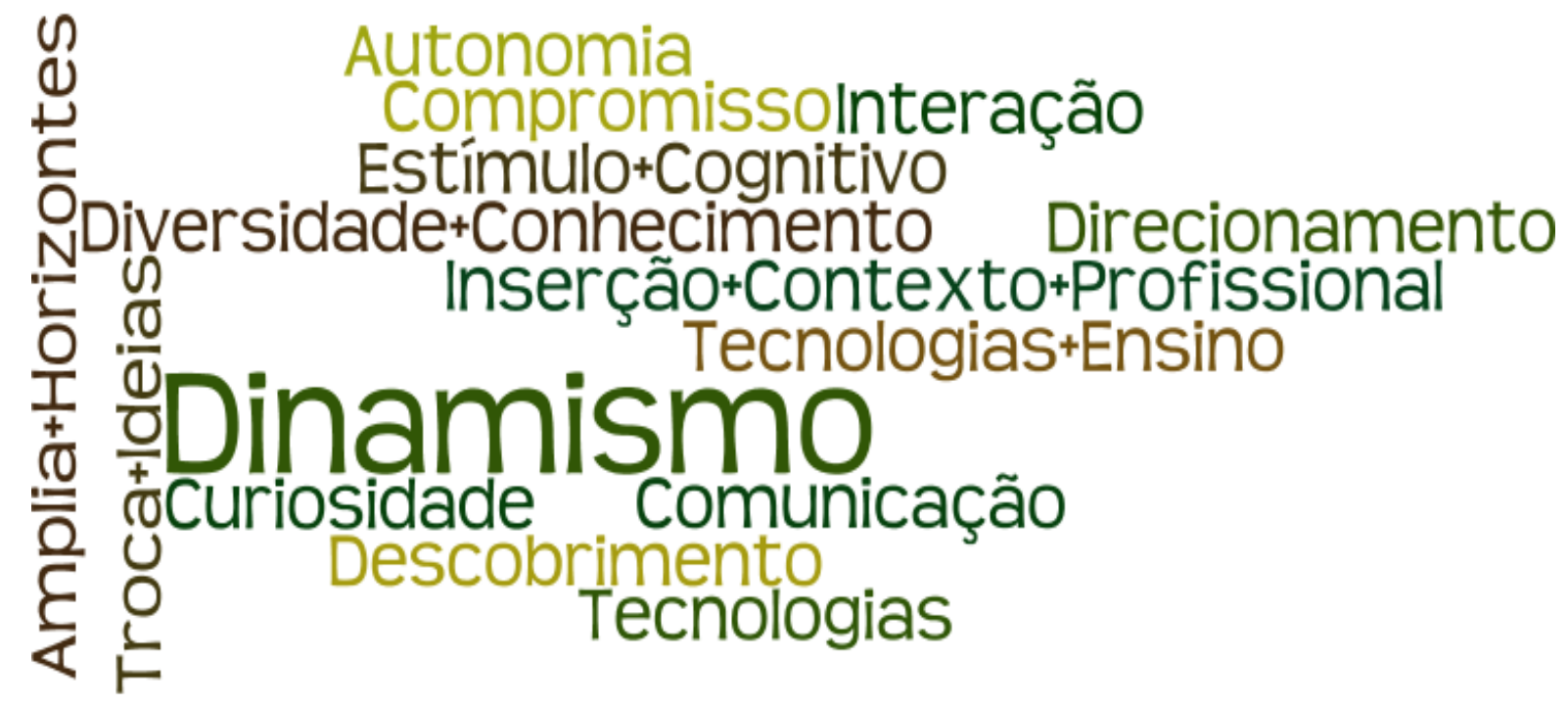

Fonte: Imagem do Wordle gerada pelos autores. 2019.

A incorporação do uso de ferramentas da tecnologia da informação e comunicação no ensino já é rotina entre as estratégias adotadas para o ensino e aprendizagem. Nesse sentido, a inserção tecnológica é um fator essencial para a difusão, familiarização e utilização das tecnologias de informação e comunicação nos campos sociais. O uso dessas tecnologias tem aprimorado a aprendizagem dos estudantes (SILVA; SOARES, 2018).

Durante as considerações o moderador chamou atenção para apontar que durante o desenrolar das oficinas foram usadas as metodologias ativas painel integrado, grupos de discussão, cine-vídeo, resolução de questões problema, síntese e tempestades de ideias.

Ao final da oficina foi distribuída aos docentes uma ficha de avaliação da oficina. 0 formulário era breve e solicitava que o participante marcasse com um "X" sobre o emoticon que melhor representava sua avaliação da oficina. Entre os emoticons havia o indicativo de ótimo, bom, regular e ruim. Nessa abordagem a oficina foi avaliada como ótima por 25 (92,6\%) participantes e boa por $02(7,4 \%)$.

A segunda abordagem do formulário solicitou que o participante marcasse os emoticons que indicava seus sentimentos ao encerrar a oficina. As alternativas de emoticons 
eram: preocupado, inspirado, surpreso, cansado, com dúvida, quero mais e indiferente. Obteve-se 20 (66,7\%) marcações sobre o emoticon inspirado, 08 (26,7\%) sobre quero mais, 01 $(3,3 \%)$ sobre preocupado e $01(3,3 \%)$ sobre surpreso. Nesta abordagem o participante podia marcar em mais de um emoticon.

A realização de ações de feedback é imprescindível para obtenção de retorno, resposta às ações, ou ainda, para dialogar sobre acontecimentos internos, atitudes e resultados (KUHN; BERWIG; PINTO, 2015).

No ensino é importante que os professores busquem feedback de suas ações para transmitir segurança ao estudante para que este possa realizar um aprendizado consciente, significativo e reflexivo (FARIAS et al., 2015).

\section{CONSIDERAÇÕES FINAIS}

A oficina apresentou como uma importante ferramenta para capacitação pedagógica, devido a sua boa aceitação pelos docentes, associado a isso é uma ferramenta para provocar, questionar e, sobretudo inspirar os docentes para práticas de ensino e aprendizagem que tornem os acadêmicos mais autônomos na produção de seus conhecimentos. De forma que as abordagens metodológicas da própria oficina possam caracterizar estratégias a serem estendidas para as salas de aula.

As produções elaboradas na Oficina mostram que os docentes adotam o uso metodologias ativas nas aulas, reconhecem o cenário de atuação da IES e público que atende, têm visão bastante positiva em relação à sua formação e prática profissional e menos positiva em relação aos acadêmicos sob sua responsabilidade de formação. 


\section{REFERÊNCIAS}

ALBERTI, T. F.; ABEGG, I.; COSTA, M. R. J.; TITTON, M. Dinâmicas de grupo orientadas pelas atividades de estudo: desenvolvimento de habilidades e competências na educação profissional. Rev. bras. Estud. pedagog. (online), Brasília, v. 95, n. 240, p. 346-362, maio/ago., 2014. Disponível em: http://www.scielo.br/pdf/rbeped/v95n240/06.pdf. Acesso em: 03 jul. 2019.

BAGATINI, L.; SCHORR, M. C. Metodologias Ativas no Ensino Profissionalizante: uma experiência na disciplina de pesquisa e desenvolvimento de produtos. Ensino, Saúde e Ambiente, v. 12, n. 1, p. 123-142, abr., 2019. Disponível em: http://periodicos.uff.br/ensinosaudeambiente/article/view/21531. Acesso em: 04 jul. 2019.

BORBA, M. C.; OECHSLER, V. Tecnologias na educação: o uso dos vídeos em sala de aula. R. bras. Ens. Ci. Tecnol., Ponta Grossa, v. 11, n. 2, p. 181-213, mai./ago. 2018. Disponível em: https://doi.org/10.3895/rbect.v11n2.8434. Acesso em 06 out. 2020.

SOUZA, V. A. Oficinas Pedagógicas como Estratégia de Ensino: uma visão dos futuros professores de ciências naturais. Trabalho de Conclusão de Curso - Licenciatura em Ciências Naturais, Universidade de Brasília, Faculdade UnB Planaltina, 2016, 35p. Disponível em: https://bdm.unb.br/bitstream/10483/14170/1/2016_ValdeciAlexandredeSouza_tcc.pdf. Acesso em: 06 out. 2020.

FARIAS, C. M. L.; CARDOSO, B. D. F.; SANTOS NETO, E. T.; CARVALHO, R. B.; CURTIS, D. A. Feedback no processo de aprendizagem: percepção dos estudantes de Odontologia em uma universidade brasileira. Revista da ABENO, v. 15, n. 3, p. 35-42, 2015. Disponível em: https://doi.org/10.30979/rev.abeno.v15i3.160. Acesso em: 06 out. 2020.

FONSECA, D. J.; MENDES, R. R. L. Oficinas pedagógicas: analisando sua contribuição para a formação inicial de professores de Ciências e Biologia. Ciência em Tela, v. 5, n. 1, p. 1-12, 2012. Disponível em: http://www.cienciaemtela.nutes.ufrj.br/artigos/artigo2.23.pdf. Acesso em: 24 abr. 2019.

FREITAS, A. L. S.; GRILLO, M. C.; GESSINGER, R. M.; LIMA, V. M. R. Capacitação docente: um movimento que se faz compromisso [recurso eletrônico]. - Dados eletrônicos. - Porto Alegre : EDIPUCRS, 2010, 205p. Disponível em: http://www.pucrs.br/edipucrs/capacitacaodocente.pdf. Acesso em: 23 abr. 2019.

INOCENTE, L.; CASTAMAN, A. S.; VIEIRA, M. L. Painel Integrado: material didático-pedagógico facilitador do processo de ensino e aprendizagem. XIII Congresso Nacional de Educação (EDUCARE). IV Seminário Internacional de Representações Sociais, Subjetividade e Educação. VI Seminário Internacional sobre Profissionalização Docente. p. 4096-4107, 2017. Disponível em: https://educere.bruc.com.br/arquivo/pdf2017/25458_12179.pdf. Acesso em: 29 jun. 2019.

MiChelato, S. Universidade Estadual do Norte do Paraná. Pró-Reitoria de Extensão e Cultura. Programa de Desenvolvimento Educacional. Repensando os diferentes encaminhamentos metodológicos no processo ensino aprendizagem da Geografia. Cornélio Procópio, 2013, 25p. Disponível em: http://www.diaadiaeducacao.pr.gov.br/portals/cadernospde/pdebusca/producoes_pde/2013/2013_uenp_geo_pdp _susyane_michelato.pdf. Acesso em: 01 jul. 2019.

SILVA, V. A.; SOARES, M. H. F. B. O uso das tecnologias de informação e comunicação no ensino de Química e os aspectos semióticos envolvidos na interpretação de informações acessadas via web. Ciênc. Educ., Bauru, v. 24, n. 3, p. 639-657, 2018. Disponível em: http://dx.doi.org/10.1590/1516-731320180030007. Acesso em: 02 jul. 2019.

KUHN, I. N.; BERWIG, A.; PINTO, R. C. F. O feedback como potencial de desempenho na gestão de pessoas: um estudo de caso. XV Colóquio Internacional de Gestão Universitária - CIGU. Desafios da Gestão Universitária no Século XXI. Mar del Plata, Argentina, 2, 3 e 4 de dez. de 2015. Disponível em: https://repositorio.ufsc.br/bitstream/handle/123456789/136046/101_00152.pdf?sequence=1\&isAllowed=y. Acesso em: 04 jul. 2019.

\section{$(\mathrm{cc}) \mathrm{Br}$}

Este trabalho está licenciado com uma Licença Creative Commons - Atribuição 4.0 Internacional. 